\title{
Viewpoint of the Scientific Community
}

\author{
W. N. HUBBARD, Jr., M.D.
}

$I^{1}$ T IS POSSIBLE to look upon grants management in its relation to the scientific community as an exercise in bringing to this group a keener awareness of the significance of fiscal accountability for categorical efforts. In this context, the importance of the budget as a fiscal expression of program would be emphasized. The program itself ideally would be a statement of the nature of the effort which the scientist himself wished to undertake. This program would be developed and evaluated on the basis both of its scientific merit and its relevance to the interests of the potential supplier of funds. The budget would then be prepared as a reflection of this program and be altered only as the program itself changed. At the conclusion of the described effort, expenditures within the budget would have been made in such a way that it would be possible retrospectively to confirm that expenditures had been for the originally approved purposes.

It is difficult to imagine why such an obviously reasonable effort should lead to a "crisis of confidence" between those responsible for awarding and managing grants and the scientific community. Rather than discuss the operational technicalities, I should like to describe what I believe to be some of the fundamental reasons for this present crisis.

\section{Meaning and Purpose of Grant}

The word "grant" usually has a different meaning for the grantor, the recipient institution, and the individual scientist. The grantor typically has in mind an attack on a defined problem in health. The recipient institution frequently looks upon the grant as a means of supporting a segment of the much broader program of the total institution. The scientist typically views the grant as a recognition of his personal capability to undertake a scientific effort that has been conceived by him and considers that the grant, in this unique sense, is his.

The congressional intent in appropriating Federal health research funds is to support the resolution of health problems that have been recognized in the people of the United States. These specific health problems are expressed by the names of the principal disease states related to premature death and to impaired capacity to function. Funds are appropriated separately for each category according to the relative importance that it seems to have in the health of the community. However, these categories represent a set of such highly complex phenomena that they cannot actually be approached intact and directly by the scientific method.

One limitation of scientific explanation is that where organized complexity increases, the probability of a satisfactory explanation based on highly certain and reproducible observations which are the foundation of scientific inquiry sharply decreases. Where there are large sets of systematically interdependent variables that are characteristic of living systems, the phenomena that reflect the interaction of these multiple variables must be dealt with by a reductionist approach.

Dr. Hubbard is dean of the medical school and professor of internal medicine, University of Michigan, Ann Arbor. 
Our present mathematics and computer technology cannot deal with the level of complexity that is reflected in a human being. Even such concepts as heart disease, cancer, aging, mental illness, mental retardation, and social delinquency are all phenomena of such great complexity that we must now approach their understanding and scientific study by laboriously reducing them to arbitrary smaller components that are subject to direct examination. It is, of course, possible to attempt to study a single pair of variables within these complex systems, but it is a highly unlikely assumption that definitive causal relationships can thereby be deduced. At the outset then, the complexity of the health problems that are to be solved as opposed to the limited capacity of science as we know it today to deal directly with such problems represents a dilemma.

Aggravating this issue is the observation that when complex phenomena have been reduced to scientifically manageable components, these components typically have no unique or restricted relevance to the original problem. They can be related to the categorical health problem, principally by intuition, common sense, or general observation. As a result, the purpose of studying these components has no more necessary relationship to the function of health from which they are derived than the isolated components of an automobile have to its function of transportation. There thus develops a fundamental logical problem created by the discrepancy between the intent of the research appropriation and the means by which this intent is served by the scientist. Many of the misunderstandings that have arisen between the research managers and the scientific community are related to this logical dilemma.

The nature of the grant must be adapted, then, to provide an accommodation between the parties to this dilemma. Like a happy marriage, the grant is a union of governmental and scientific communities. In a happy marriage, both parties must have a broad area of common purpose and a mutual satisfaction with the fruits of the union. Both parties must be strengthened by the union itself. Neither can allow himself to dominate to the point of imperiling the essential individuality of the other. If the condition of the grant is clearly destructive to the interests of one or the other party, then a dignified separation device that will protect the fruit of the union (scientitic knowledge) must be at hand. The union itself must have an important value so that each party is willing to submerge his more selfish interests to the union's purposes and be able to gain satisfaction, in part, through the satisfaction of the partner's needs.

The defined purpose of a grant inevitably confronts the opportunistic nature of creative scientific effort. Here serendipity can have a greater value than the planned programs. The scientist must necessarily view his freedom to depart from preconceived plans as an essential component of his intellectual role. The grantor, however, is necessarily less concerned with this aspect of the scientist's contribution and seeks a continuing effort that has obvious relevance to the initial plans of the research. It is important then to understand that the intent of the grantor, that is, an increase in purposeful or applicable knowledge relevant to a specific human problem, is by nature at odds with the discipline of the scientific method itself.

Concern with the human condition falls outside of logical systems of science although these systems are applicable to a study of phenomena in humans. Although the scientist may be motivated personally by humanistic values and concerns, his actual scientific research does not deal with humanistic purposes. The scientist and the nonscientist have great difficulty in communicating when discussing this research. This difficulty is to be anticipated since to the scientist the fruits of scientific inquiry are their own sufficient justification. In the nonscientist's value system, however, scientific knowledge is justified only when it can be used to alter phenomena that he perceives will affect his own welfare. It is because of this difference in value systems that a good deal of suspicion exists on the part of the nonscientist which leads him to ask for more control of scientific activity as a prerequisite for proper stewardship of public funds.

The grant has been described by Dr. James Shannon, director of the National Institutes of Health, as a "contingent gift." This terminology seems to me to reflect nicely the role of the grant in accommodating the intrinsic differ- 
ence between the concepts of the grantor and the actual operative realities of scientific research.

\section{Managerial Authority}

Much has been written about the function of the manager in our modern society. A whole new literature has become available in the last two decades dealing with the managerial role. The very concept of a social organization implies the existence of authority and the availability of some decision-making process. Since the scientist requires institutional organization for his efforts, he inevitably becomes involved, albeit against his will and better judgment, in these institutional problems of authority and decision making.

I would assert at the outset that the scientist must be an influential part of the decision-making process if his productivity is not to be inhibited. The managerial role within the organization that includes the scientist will be more effective and influential when the manager works with "the consent of the governed" rather than by decree. It is only by involving the scientist in the authority hierarchy and in the decision-making process that it is possible to engage him in direct responsibility for institutional and social goals as well as his own personal ones. By such engagement, one will achieve much more active participation than could ever be gained through a purely downward movement of authority from some centralized power structure. This is not a novel concept since it is the basis of the strength of the democratic process. In terms of management theory, however, it departs sharply from traditional concepts.

Traditional theories on sources of managerial strength and authority are drawn from industrial, business, governmental agency, and military settings. These institutions are very different social structures than the university, which is the most common social setting for the scientist. It is highly probable that the organizational settings which have given rise to traditional management theories are not suitable for translation into university administration. The idea of purchasing a man's time for an agreed output and then having authority over that time so that the product is assured represents the foundation of traditional mana- gerial stewardship. The basic authority of the manager in such a setting is derived from his control of the economic motivations of the worker. Relatively, the manager is much less concerned with noneconomic motivations such as personal status, self-importance, independence, peer recognition, and general reputation.

Corporations and managers of large enterprises are increasingly recognizing the significance of these noneconomic factors in their personnel practices. In the university setting, however, and for the scientist, these noneconomic factors are frequently of a distinctly high order of importance. In the university, where market prices for professional skills are rarely paid entirely in dollars, those who have managerial authority deal heavily with both noneconomic and economic considerations.

The high loyalty of scientists to their own professional groups must be appreciated. These loyalties may exceed those to his department, school, and university. However, if he is isolated from the institutional setting, his professional identity itself is threatened. In the management of grants, Rensis Likert, director of the Institute for Social Research, University of Michigan, has described the need for "a high level of reciprocal influence." The managerial function is properly conceived, in my opinion, as serving this purpose.

\section{Scientific Community}

What is the nature of the scientific community as we know it? I have alluded to the necessity of the scientist working in an institutional setting in order to be effective. The institutions that have historically fostered science most successfully are the universities plus a small number of institutes which have adopted the patterns of the academic tradition. The Rockefeller Institute and the intramural program of the National Institutes of Health in the United States can represent models, while the Pasteur Institute in Paris and the Weizman Institute in Jerusalem would expand the number of examples. Each university and institute is a micro society, created to support the purposes of knowledge-its discovery, dissemination, and preservation. If this basic purpose is not accepted by the larger society, then the 
value of these institutions is threatened. The nature of the threat is that the knowledge must have relevance that is recognizable in the terms of the grantor without appropriate consideration of the nature of scientific inquiry. The analogy of the goose and the golden egg is clear.

If research itself is segregated as a function from other university roles, then the nature of the academic community is jeopardized. The institute concept is dependent on the academic tradition of the university. It is not a substitute for such tradition nor does it fit congenially within the greater university setting. It can, however, draw from the great strength of the university tradition so long as its derivative nature is clearly recognized.

Within the university setting, there has been criticism of the increasing amounts of research conducted within traditional academic departments. It is alleged that the education of college students today is deteriorating because of the usurpation of faculty interest by research. If the educational experience really is deteriorating, it is difficult for me to understand the greatly increasing demand for the output of this "degraded" environment.

One of the important components of the university tradition is stability in support of the community of scholars. In this context the scientific community fears the price of rigidity that must be paid if this stable support is to be related to a categorical area of research. The unpredictable component in creativity can be readily smothered by a soothing mass of mediocre effort if accounting for time and effort is allowed to substitute even in part for scientific excellence.

Our present level of knowledge, no matter how effectively distributed, cannot offer a resolution to the health problems that we face today. The critical responsibility in grants management is to resolve the crisis of confidence that has been allowed to develop between the scientific community and those responsible for the award and administration of scientific support. The restitution of confidence will be based on mutual understanding. No set of regulations or elaboration of business and fiscal devices can substitute for this understanding.

\section{Housing for Migrants}

The Division of Community Health Services of the Public Health Service and the Agricultural Engineering Research Division of the Agricultural Research Service will provide funds for a joint project to design and test improved housing facilities for migrant farmworker:s.

Under the project, present types of migrant housing will be evaluated. Plans will then be developed for the construction of improved low-cost housing designed for short-term occupancy by migrant workers, and prototypes will be erected for testing in various locations having different climates.

The project is designed to result in the provision of improved housing for seasonal farm laborers, particularly in the area of short-term occupancy where, heretofore, economic factors have militated against the provision of healthfully adequate housing. This will require a reexamination of thinking concerning legal restriction governing such housing, since the application of generally accepted minimal standards developed for urban, year-round occupancy housing becomes economically unfeasible in the area of short-term occupancy. 